\title{
Differences in huperzine A yield when different amino acids were added for in vitro thallus culture of Huperzia serrata (Thunb)Trev and gene expression analysis
}

\section{Ye YuXuan}

Jiangxi Normal University https://orcid.org/0000-0002-1143-0212

Tu YiSheng ( $\nabla$ ysttz2012@163.com )

Yu Xiao

Jiangxi Normal University

Huang Qian

Jiangxi Normal University

Yuan Huihui

Jiangxi Normal University

Research article

Keywords: in vitro Huperzia serrata culture, huperzine A, transcriptome sequencing, differentially expressed genes, real-time fluorescence quantitative PCR

Posted Date: February 3rd, 2020

DOI: https://doi.org/10.21203/rs.2.22200/v1

License: (1) This work is licensed under a Creative Commons Attribution 4.0 International License. Read Full License 


\title{
Differences in huperzine A yield when different amino acids were added for in vitro thallus culture of Huperzia serrata (Thunb)Trev and gene expression analysis
}

YE Yu-xuan,TU Yi-sheng*, YU Xiao, HUANG Qian, YUAN Hui-hui College of Life Sciences, Jiangxi Normal University, Nanchang 330022, China

\begin{abstract}
Background : the secondary metabolite of $H$. serrata, huperzine A (HupA) can be used in the treatment of Alzheimer's disease and can improve the cognitive function of patients. The use of in vitro culture and secondary metabolism engineering to obtain secondary metabolites is the most effective method to solve a lack of HupA sources and protect $H$. serrata as a natural resource. This study was based on the in vitro thallus culture conditions for $H$. serrate, and different concentrations of alkaloid precursor amino acids (lysine, aspartic acid, and trytophan) were added. We found that addition of different amino acids to thallus cultures had different effects on HupA accumulation. Transcriptome sequencing was carried out on thalli with significant differences in the HupA content due to treatment with different amino acids for differential analysis, and real-time fluorescence quantitative PCR was used for validation to examine the functional genes involved in exogenous amino acid regulation of HupA accumulation in thalli.
\end{abstract}

Results : We found that addition of $1 \mathrm{mmol} \cdot \mathrm{L}^{-1}$ aspartic acid (D) solution promoted HupA accumulation, at a level of $84.05 \mu \mathrm{g} \cdot \mathrm{g}^{-1}$ dry weight (DW), which was 1.29 -fold that of the control (CK: $\left.65.15 \mu \mathrm{g} \cdot \mathrm{g}^{-1} \mathrm{DW}\right)$. Addition of $4 \mathrm{mmol} \cdot \mathrm{L}^{-1}$ lysine $(\mathrm{K})$ solution significantly inhibited HupA accumulation, at a level of $48.42 \mu \mathrm{g} \cdot \mathrm{g}^{-1} \mathrm{DW}$, which was 0.75 -fold that of the control.

Transcriptome sequencing-bioinformatics alignment analysis of the aforementioned materials showed that in GO alignment analysis, functions were annotated for 16,258 unigenes. From the statistical analysis of the DEGs of the three groups, we found that there were 1046, 782, and 1586 DEGs for CK vs D, CK vs K, and D vs K, respectively, with D vs $\mathrm{K}$ having the most DEGs. DEGs that were enriched in KEGG metabolic pathways and validated by fluorescence quantitative PCR included PANK1, GDH2, APX, HA1, ND4L, and COX1. 
Conclusions : The above results showed that HupA content differences in D and K treatments were directly proportional to DEGs. Gene expression differences are the molecular basis that affects HupA accumulation in in vitro thallus cultures. PANK1 and $G D H 2$ encode enzymes that synthesize an alkaloid intermediate. Therefore, PANK1 and GDH2 may be key enzymes involved in the biosynthesis of HupA precursors.

Keywords: in vitro Huperzia serrata culture, huperzine A, transcriptome sequencing, differentially expressed genes, real-time fluorescence quantitative PCR

*Correspondence: ysttz2012@163.com

College of Life Sciences, Jiangxi Normal University, No. 99 Ziyang Avenue, nanchang county, nanchang city, jiangxi province, China

Full list of author information is available at the end of the article 


\section{Background}

Toothed clubmoss (Huperzia serrata (Thunb)Trev) is also known as firmoss and is a commonly used Chinese herbal medicine. $H$. serrata belongs to the family Huperiaceae and the genus Huperzia Bemh and is a fern. In China, H. serrata is mainly located in eastern and southeastern China ${ }^{[1]}$. Studies have showed that the secondary metabolite of $H$. serrata, huperzine A (HupA), can be used in the treatment of Alzheimer's disease and can improve the cognitive function of patients ${ }^{[2-3]}$. The use of in vitro culture and secondary metabolism engineering to obtain secondary metabolites is the most effective method to solve a lack of HupA sources and protect H. serrata as a natural resource.

Substantial work has been performed for in vitro culture of $H$. serrata since $2012^{[4,5,8 \text {, }}$ ${ }^{21,}{ }^{18]}$ and an $H$. serrata culture has been obtained that can accumulate HupA, the thallus ${ }^{[4]}$. Further research found that the thallus is the best culture state for HupA synthesis $^{[5]}$. HupA is an alkaloid secondary metabolite, and alkaloids are mostly synthesized from amino acids ${ }^{[6]}$. Exogenous amino acids aid in plant growth and regulate secondary metabolites in plants. Early researchers added $0.2-1.0 \mathrm{mmol} \cdot \mathrm{L}^{-1}$ phenylalanine, phenylpropionylglycine, serine, and glycine to MS culture medium in Taxus chinensis suspension cultures. Results showed that these amino acids can significantly increase the yield of paclitaxel and other taxanes ${ }^{[7]}$. Ye et al. conducted in vitro induction studies on $H$. serrata thalli in 2017 and found that hydrogen peroxide has good induction effects on thalli ${ }^{[8]}$. They established several asexual lines of $H$. serrata thalli with different cumulative HupA levels.

Transcriptome sequencing is used for cDNA sequencing of plants to supplement and expand the genetic databases of species. This technique is being increasingly applied to genetics research for plants with no reference genomes. In 2015, Zhang et al. reported the isolation of an endophytic strain ES026 from $H$. serrata plants. Subsequently, they obtained RNA from this strain for sequencing analysis and individually validated the expression of copper amine oxidase (CAO) in the roots, stems, and leaves of $H$. serrata. They found that CAO may participate in HupA biosynthesis and may play a crucial role in regulating HupA yield in ES026 ${ }^{[9]}$. In 2017, Yang et al. reported the transcriptome analysis of four different $H$. serrata tissues (roots, stems, leaves, and sporangias) and identified $L D C, C A O$, and $P K S$ in transcripts $^{[10]}$. 
This study was based on the in vitro thallus culture conditions for $H$. serrate, and different concentrations of alkaloid precursor amino acids (lysine, aspartic acid, and trytophan) were added. We found that addition of different amino acids to thallus cultures had different effects on HupA accumulation. Transcriptome sequencing was carried out on thalli with significant differences in the HupA content due to treatment with different amino acids for differential analysis, and real-time fluorescence quantitative PCR was used for validation to examine the functional genes involved in exogenous amino acid regulation of HupA accumulation in thalli.

\section{RESULTS}

Effects of adding different amino acids on thallus growth and proliferation and

\section{HupA accumulation}

Table 1 shows the thallus HupA content and dry matter accumulation under different concentrations of 3 amino acid treatments. The addition of different concentrations of $\mathrm{K}$ resulted in varying degrees of inhibitory effects on thallus HupA accumulation: As concentration increased, inhibition was significantly increased. However, 0.5-2 $\mathrm{mmol} \cdot \mathrm{l}^{-1} \mathrm{~K}$ concentration did not significantly affect thallus dry matter accumulation. The addition of different concentrations of $\mathrm{D}$ resulted in different effects: low concentrations promoted while high concentrations inhibited thallus HupA accumulation. When the $\mathrm{D}$ concentration was $1 \mathrm{mmol} \cdot \mathrm{l}^{-1}$, thallus dry matter mass and HupA A content accumulation were significantly increased. Different concentrations of the $\mathrm{W}$ treatment did not have significant effects on thallus dry matter mass and HupA A content accumulation. From Table 2, we can see that the HupA A content was $65.15 \mu \mathrm{g}^{-\mathrm{g}^{-1}}$ in the control group; the thallus HupA content was the highest at $84.05 \mu \mathrm{g} \cdot \mathrm{g}^{-1}$ when $1 \mathrm{mmol} \cdot \mathrm{l}^{-1} \mathrm{D}$ was used for treatment; and the addition of 4 $\mathrm{mmol} \cdot \mathrm{l}^{-1} \mathrm{~K}$ resulted in the lowest thallus HupA content of $48.42 \mu \mathrm{g} \cdot \mathrm{g}^{-1}$, showing significant inhibition. 
Table 1 Effects of addition of amino acids on foliage biomass and Huperzine A

\begin{tabular}{cccc}
\hline $\begin{array}{c}\text { Different amino acid } \\
\begin{array}{c}\text { concentrations } \\
\left(\mathrm{mmol} \cdot \mathrm{L}^{-1}\right)\end{array}\end{array}$ & $\begin{array}{c}\text { Relative growth rate } \\
(\%)\end{array}$ & Dry weight $\mathrm{g} \cdot \mathrm{L}^{-1}$ & HupA content $\left(\mu \mathrm{g} \cdot \mathrm{g}^{-1}\right)$ \\
\hline CK & $2004.03 \pm 1.23$ & 8.07 & $65.15 \pm 0.58^{\mathrm{de}}$ \\
K 0.5 & $1698.46 \pm 0.26$ & 11.70 & $64.59 \pm 1.62^{\mathrm{d}}$ \\
K 1 & $2082.95 \pm 0.58$ & 10.01 & $53.50 \pm 0.37^{\mathrm{b}}$ \\
K 2 & $2063.12 \pm 0.49$ & 10.05 & $48.94 \pm 1.24^{\mathrm{a}}$ \\
K 4 & $2018.25 \pm 1.65$ & 8.44 & $48.42 \pm 0.66^{\mathrm{a}}$ \\
D 0.5 & $1988.24 \pm 1.21$ & 7.83 & $72.09 \pm 0.95^{\mathrm{g}}$ \\
D 1 & $2483.32 \pm 0.63$ & 9.77 & $84.05 \pm 0.71^{\mathrm{h}}$ \\
D 2 & $2101.21 \pm 0.42$ & 8.20 & $67.54 \pm 0.65^{\mathrm{ef}}$ \\
D 4 & $1669.00 \pm 0.64$ & 6.61 & $62.77 \pm 1.58^{\mathrm{d}}$ \\
W 0.5 & $2044.95 \pm 0.98$ & 7.29 & $57.91 \pm 0.88^{\mathrm{c}}$ \\
W 1 & $2053.55 \pm 0.55$ & 7.53 & $68.71 \pm 0.37^{\mathrm{f}}$ \\
W 2 & $1875.55 \pm 1.26$ & 6.9 & $63.56 \pm 0.51^{\mathrm{g}}$ \\
W 4 & $2345.78 \pm 0.47$ & 8.90 & $62.04 \pm 0.49^{\mathrm{g}}$
\end{tabular}

Note: HupA content data are "mean \pm standard error"; different lowercase letters indicate a significant difference between the values $p<0.05$.

\section{Transcriptome data screening and gene library construction}

Based on the HupA content under amino acid treatment, $1 \mathrm{mmol} \cdot \mathrm{l}^{-1} \mathrm{D}$ treated thalli were selected as high-yielding HupA thallus material (D), $4 \mathrm{mmol} \cdot \mathrm{l}^{-1} \mathrm{~K}$ treated thalli were selected as low-yielding HupA thallus material $(\mathrm{K})$, and pure water-treated thalli were considered as the control (CK). RNA sequencing was carried out on these samples. Triplicate RNA sequencing was carried out on the 3 treatments to obtain raw reads for 9 transcriptome groups (Table 2). Raw reads with adapters and low-quality reads were removed from raw reads to obtain clean reads. Trinity software ${ }^{[11]}$ was used on all clean reads to obtain 128496 unigenes with an average length of $625 \mathrm{bp}$ (Table 3). 
Table 2 Transcription sequencing results of the thallus

\begin{tabular}{llll} 
sample & $\begin{array}{l}\text { Total number of } \\
\text { sequences }\end{array}$ & $\begin{array}{l}\text { High quality sequence } \\
\text { number }\end{array}$ & $\begin{array}{l}\text { High quality sequence } \\
\text { percentage }\end{array}$ \\
\hline CK1 & $43,228,398$ & $42,747,912$ & 98.88 \\
CK2 & $49,483,194$ & $49,039,852$ & 99.10 \\
CK3 & $50,832,792$ & $50,549,106$ & 99.44 \\
K1 & $45,473,372$ & $45,176,264$ & 99.34 \\
K2 & $48,277,568$ & $48,041,946$ & 99.51 \\
K3 & $40,537,658$ & $40,318,394$ & 99.45 \\
D1 & $41,757,120$ & $41,535,074$ & 99.46 \\
D2 & $41,992,934$ & $41,514,984$ & 98.86 \\
D3 & $52,949,286$ & $52,502,934$ & 99.15 \\
\hline
\end{tabular}

Table 3 Statistics of assembly results

\begin{tabular}{llll}
\hline Types & contig & transcript & unigene \\
\hline $\begin{array}{l}\text { The total length of the } \\
\text { sequence (bp) }\end{array}$ & $112,833,105$ & $181,933,305$ & $80,369,585$ \\
$\begin{array}{l}\text { Total number of } \\
\text { sequences }\end{array}$ & 380,517 & 232,432 & 128,496 \\
$\begin{array}{l}\text { The average length of } \\
\text { the sequence (bp) }\end{array}$ & 296 & 783 & 625 \\
\hline
\end{tabular}

\section{GO functional annotation of unigenes}

The 128496 unigenes were aligned with the NR database, and 41114 unigenes were functionally annotated. In total, 16258 unigenes (39.54\%) were enriched in 3 major categories and 48 minor categories based on GO functional annotation (Figure 1). The first category was participation in biological processes, of which the highest proportion was cellular processes, followed by metabolic processes, and then single tissue processes. The second category of the cellular component involved the highest number of unigenes, which may be related to thallus growth and development. Of particular attention was the third category (molecular function), which mainly participated in protein binding activity and catalytic activity. Some functional groups were not aligned to unigenes, which may be due to the absence of a reference genome for alignment. 


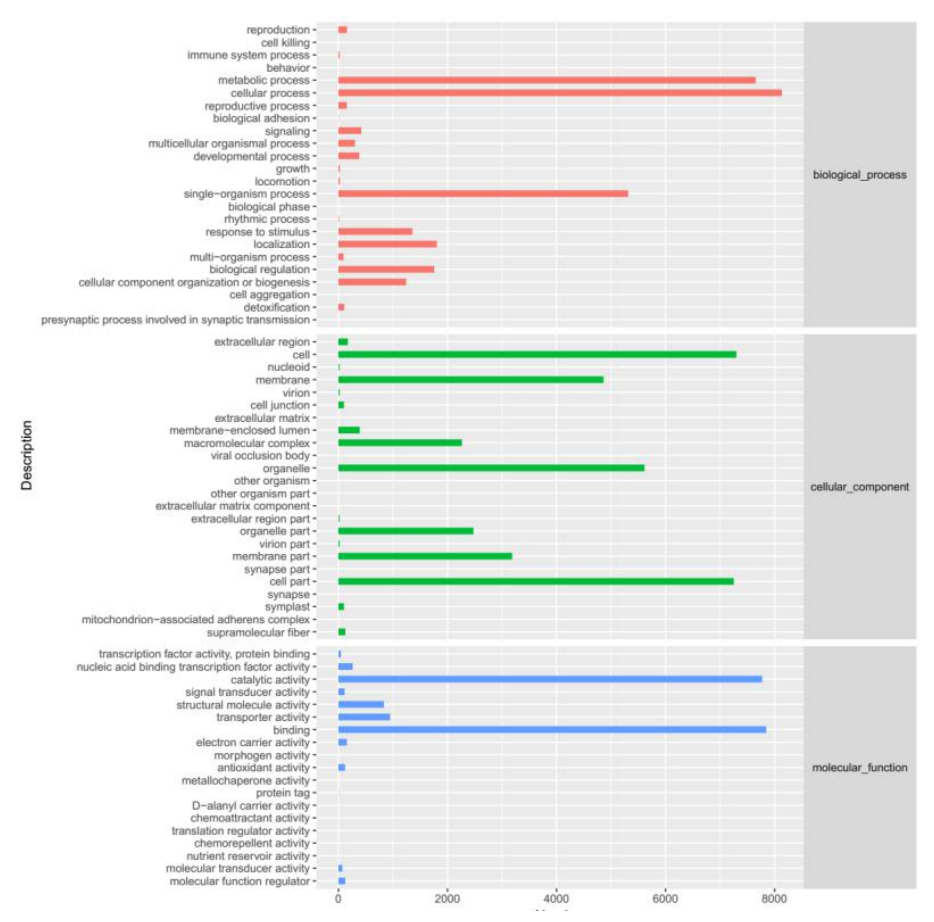

Figure $1 \mathrm{GO}$ function note

\section{Statistical and clustering analyses of differentially expressed genes (DEGs) of the three treatments}

Differential expression analysis was carried out on genes in the $\mathrm{K}, \mathrm{D}$, and CK groups. Table 4 shows the statistical results. There were 1046 DEGs for CK vs D, of which 577 genes were upregulated and 469 genes were downregulated. There were 782 DEGs for CK vs K, of which 437 genes were upregulated and 345 genes were downregulated. There were 1587 DEGs for D vs K, of which 778 genes were upregulated and 808 genes were downregulated. It can be seen that D vs $\mathrm{K}$ had the most DEGs.

Table 4 Statistics of unigene differential expression results

\begin{tabular}{ccccc}
\hline $\begin{array}{l}\text { Reference } \\
\text { sample }\end{array}$ & sample & Total DEGs & $\begin{array}{c}\text { Up-regulated } \\
\text { unigene }\end{array}$ & $\begin{array}{c}\text { Down-regulated } \\
\text { unigene }\end{array}$ \\
\hline CK & D & 1,046 & 577 & 469 \\
CK & K & 782 & 437 & 345 \\
D & K & 1,586 & 778 & 808 \\
\hline
\end{tabular}


The $\mathrm{R}$ language Pheatmap software package was used for bidirectional clustering analysis of DEGs and 9 samples from the 3 treatment groups. Figure 2 shows the results. From the inter-sample clustering results in Figure 2, we can see that triplicate DEGs clustered into one group, showing that the three treatments had consistent reproducibility, and differences between treatments were significant. From the expression clustering of DEGs on the left of Figure 2, we can see many upregulated red genes in Group D that were clustered with the corresponding green downregulated genes in Group $\mathrm{K}$ and vice versa. These DEGs may have indirect or direct relationships with HupA accumulation.

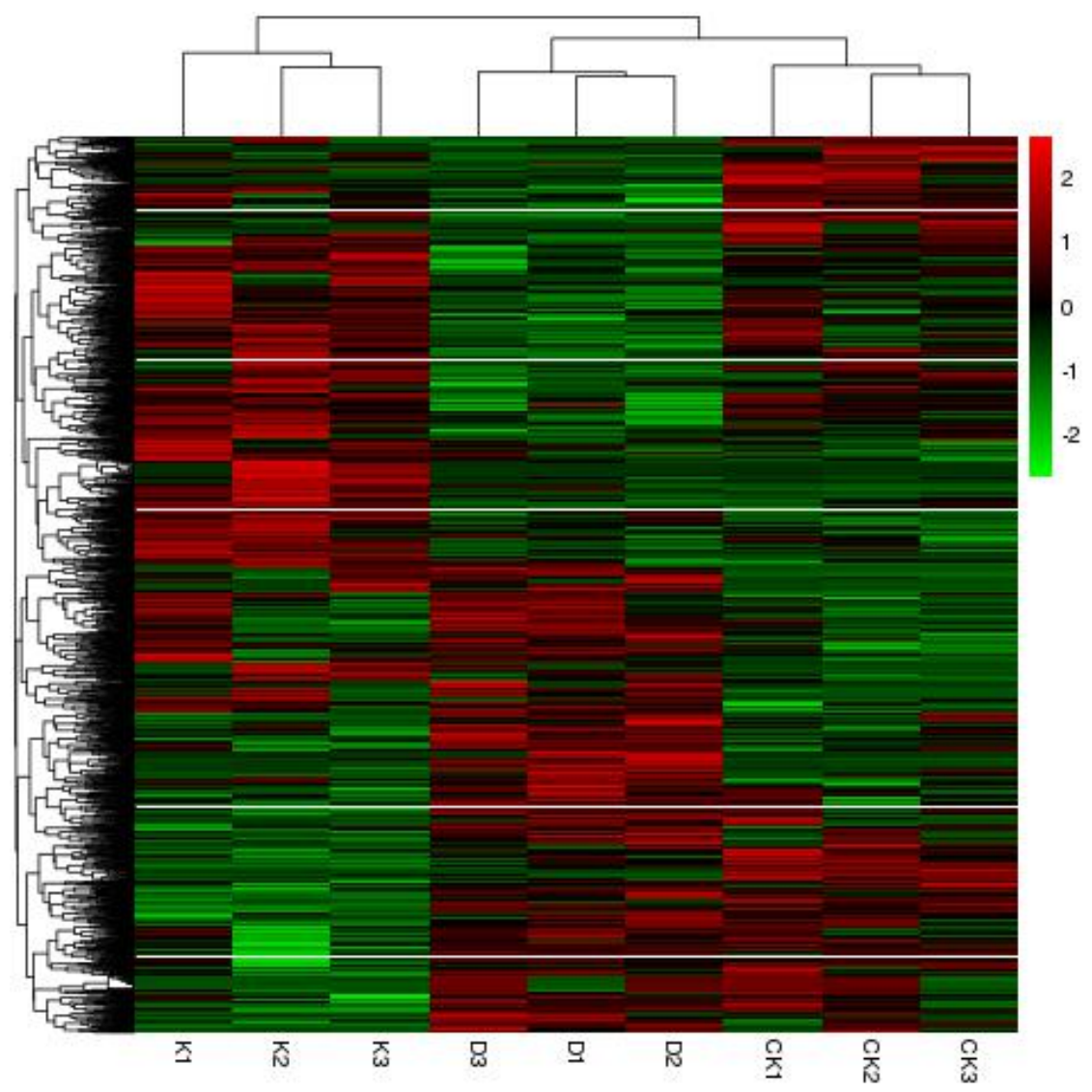

Figure 2 Cluster tree map of differentially expressed genes

Note: The vertical axis represents DEG, and the horizontal axis represents three types of treated leaflets. Green indicates low gene expression and red indicates high gene expression.

KEGG analysis of differentially expressed genes under two different amino acid treatments and $q R T-P C R$ validation 
D was used as reference samples to obtain 126 metabolic pathways of DEGs from $\mathrm{K}$ that were enriched in the KEGG database (including participation in many pathways by the same gene). In the alkaloid metabolic pathway in which amino acids were the starting point, 3 DEGs were downregulated in phenylalanine metabolism. In the pantothenate and CoA biosynthesis pathways in which pyruvate was the starting substrate, 1 DEG was upregulated and 1 DEG was downregulated under $\mathrm{K}$ treatment (Figure 3). The green rectangle EC:2.7.1.33 in Figure 6 corresponds to downregulated PANK1 under K treatment. In oxidative phosphorylation metabolic pathways, 2 DEGs were upregulated and 2 DEGs were downregulated under K treatment (Figure 4). In Figure 4, the red rectangles EC:7.1.1.2 and EC:1.9.3.1 are the two downregulated genes (ND4L and COX1), while the green rectangles EC:3.6.1.1 and EC:7.1.2.1 are the upregulated genes (inorganic pyrophosphatase and HA1). In addition, there were 3 upregulated genes under D treatment that were annotated as antioxidant enzymes, including $A P X$.

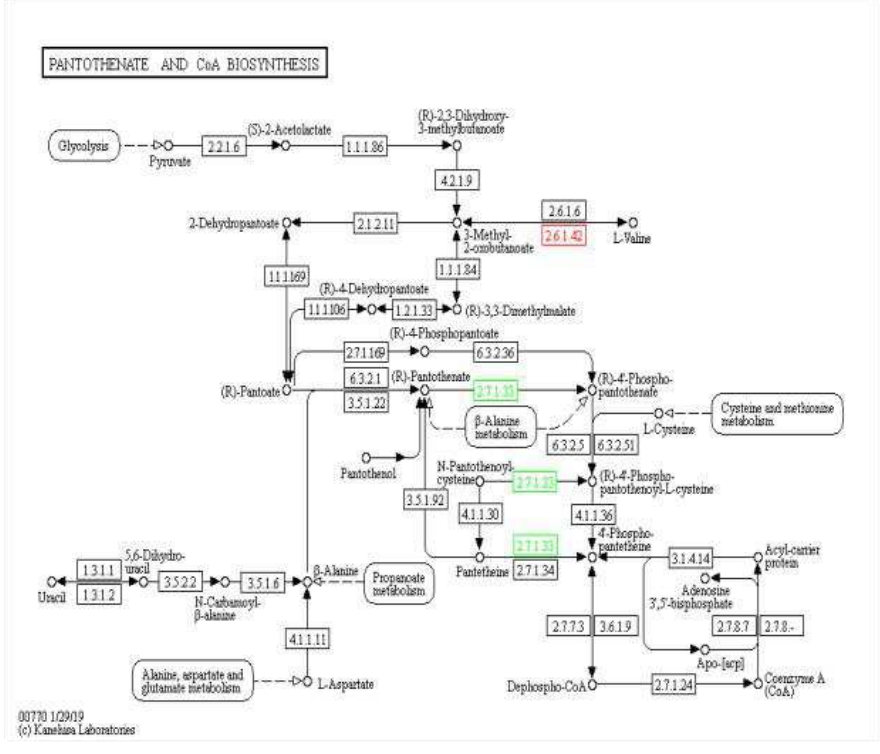

Figure 3 D VS K Pantothenate and CoA biosynthesis 


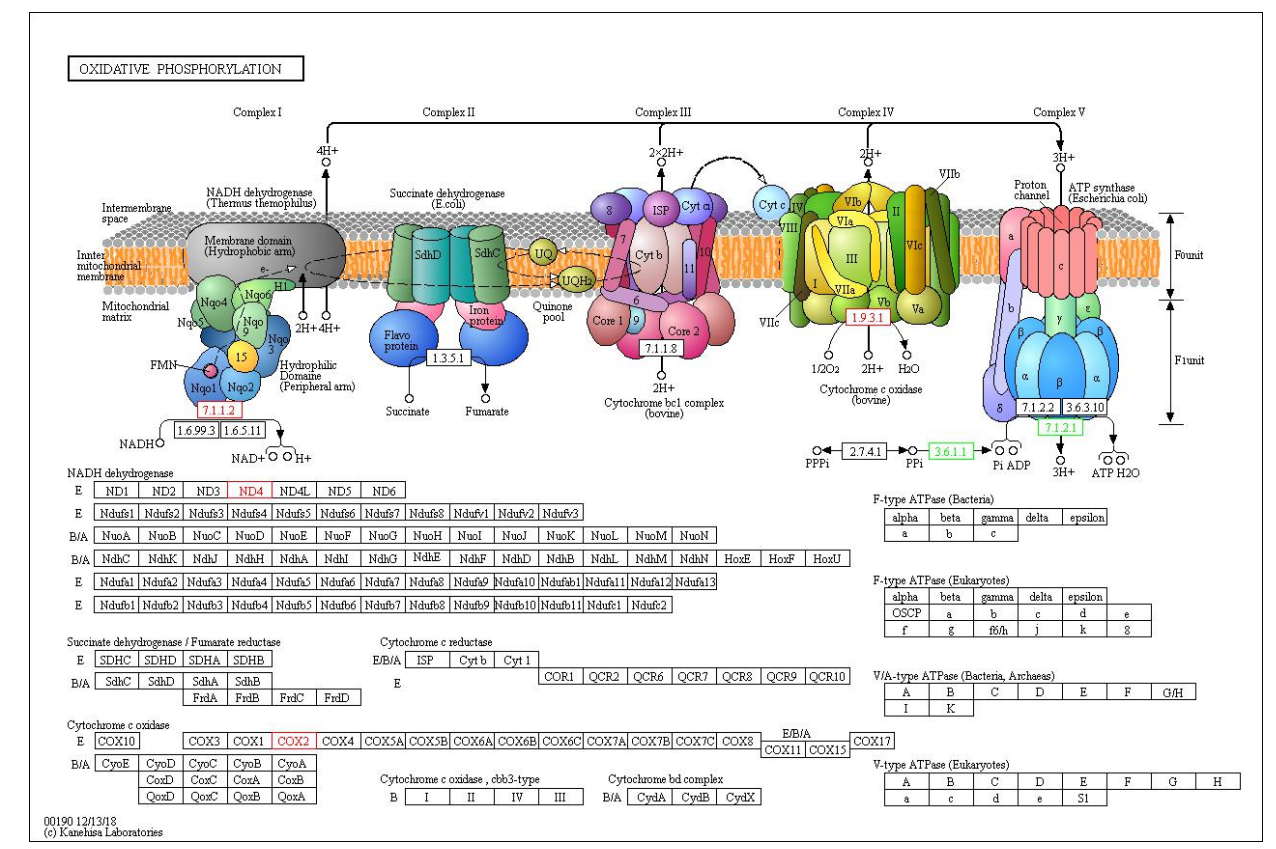

Figure 4 D vs K Oxidative phosphorylation

qRT-PCR was used to partially validate DEGs in the KEGG metabolic pathways. Results showed that 6 transcripts were identified (Figure 5). From Figure 5, we can see that the expression levels of 4 genes (PANK1, GDH2, APX, HA1) under $\mathrm{K}$ treatment were significantly lower than under $\mathrm{D}$ treatment, while the relative expression levels of 2 genes ( $N D 4 L$ and $C O X 1)$ were significantly higher than in the D treatment.

Therefore, the expression differences of $N D 4 L, C O X 1$, the $H A 1$ under $\mathrm{K}$ treatment may decrease ATP synthesis. Upregulated PANK1 expression under D treatment may increase CoA biosynthesis, which facilitates the accumulation of upstream materials for mevalonic acid (MVA) terpenoid alkaloids, and upregulated GDH2, an enzyme involved in amino acid metabolism, may increase the biosynthesis of HupA precursors. These results provided a molecular basis for a high HupA content under D treatment and a low HupA content under K treatment. 

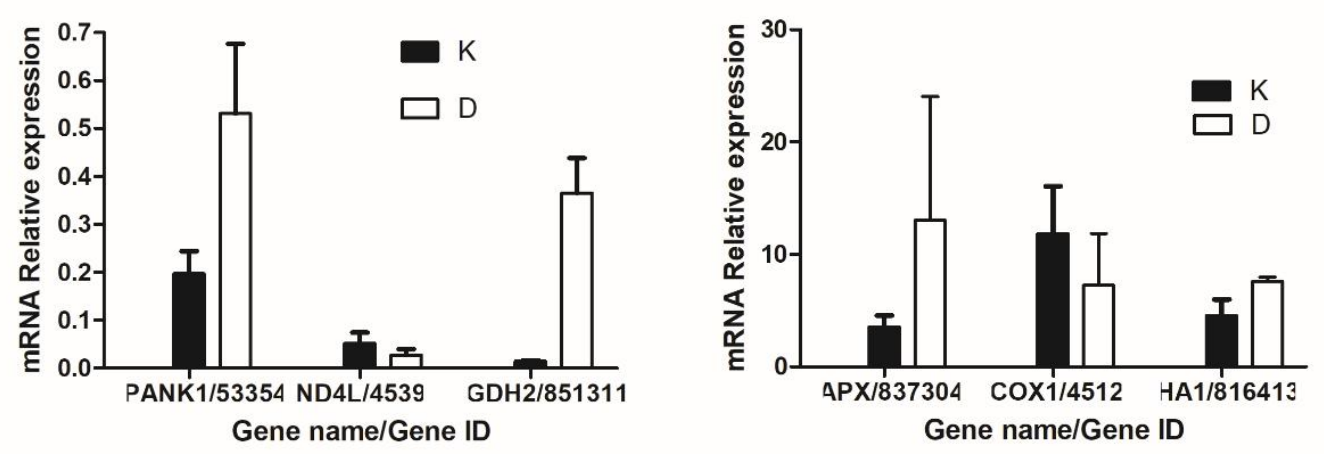

Figure 5 mRNA relative expression by qRT-PCR $\quad(\mathrm{P}<0.05)$

\section{CONCLUSION AND DISCUSSION}

Addition of the precursors of secondary metabolite alkaloids in in vitro culture can effectively increase the content of target substances in plants, and amino acids can act as precursors for in vivo metabolic processes ${ }^{[12]}$. Jiang et al. reported that addition of 5 $\mathrm{mg} \cdot \mathrm{L}^{-1}$ 5-methyl-DL-tryptophan to suspension cultures of Cephalotaxus hainanensis resulted in a cephalotaxine content that was 2.192-fold higher than that of the control $^{[13]}$. The results of this study showed that the addition of $1 \mathrm{mmol} \cdot 1^{-1} \mathrm{D}$ solution on day 40 of the culture and continuing culture to 80 days resulted in the maximum peak for dry substances and HupA accumulation in the culture, which is consistent with the results of $\mathrm{Ji}$ et al. in $2016^{[4]}$ and reported a cumulative HupA content in $H$. serrata thalli that was 1.29-fold higher than that of the control group. The addition of $4 \mathrm{mmol} \cdot \mathrm{l}^{-1} \mathrm{~K}$ solution had inhibitory effects on HupA accumulation in $H$. serrata thalli, resulting in a HupA content that was 0.75 times the value of the control group. The addition of $1 \mathrm{mmol}^{-1} \mathrm{D}$ had significant effects on promoting HupA accumulation in thalli.

Studies have reported that HupA biosynthesis may occur when lysine forms cadaverine under the action of lysine decarboxylase before undergoing a series of enzymatic reactions, such as oxidases, methyltransferases, etc ${ }^{[14-15]}$. In this study, the addition of $\mathrm{K}$ did not promote HupA accumulation, while $\mathrm{D}$ treatment promoted HupA accumulation. This shows that $\mathrm{K}$ is not the precursor for HupA biosynthesis. Transcript expression analysis and identification of differences in HupA accumulation due to the addition of different amino acids showed that PANK1 in the pantothenate and CoA metabolic pathways was upregulated under D treatment. PANK1 
participates in many amino acid metabolic pathways and is a rate-limiting enzyme for CoA biosynthesis in plants ${ }^{[16]}$. It is widely known that CoA is the raw material for synthesizing terpenes in MVA biosynthesis in the cytoplasm ${ }^{[16]}$, and some researchers proposed that HupA is a sesquiterpene alkaloid ${ }^{[17]}$. The results of this study showed that PANK1 was upregulated under D treatment, and HupA accumulation was increased while PANK1 was downregulated under $\mathrm{K}$ treatment and HupA accumulation was inhibited. Therefore, in $\mathrm{D}$ and $\mathrm{K}$ treatments PANK1 relative expression levels and accumulated HupA level were positively correlated. This linkage phenomenon in which changes in PANK1 expression affect downstream HupA accumulation suggests that PANK1 is a rate-limiting enzyme for CoA synthesis and may be a key enzyme in HupA biosynthesis in H. serrata thalli. At the same time, HAl was upregulated under D treatment, which may assist in increasing HupA accumulation, which is energy-consuming. GDH2 is a protease at the start of alkaloid synthesis for alanine, aspartic acid, and glutamic acid. The upregulated GDH2 results under D treatment validated our previous findings in which upregulation of GDH2(P93541) was associated with HupA accumulation ${ }^{[18]}$. Therefore, we believe that PANK1 and GDH2 may be two key enzymes upstream of HupA biosynthesis.

Under normal circumstances, reactive oxygen species in plants are removed by the synergistic action of antioxidants and antioxidant enzymes. When there are changes in growth conditions, the level of reactive oxygen species in plants will increase and antioxidant enzyme activities will rapidly increase to scavenge reactive oxygen species (ROS). Ye et al. reported that the antioxidant capacity of high-yielding thalli was increased ${ }^{[8]}$. Our study found that genes associated with the antioxidant enzyme system were upregulated in thalli under D treatment, of which 3 antioxidant genes were enriched with upregulated expression, of which 1 was APX. Under K treatment, APX was downregulated. APX is an enzyme that scavenges hydrogen peroxide in plants and it protects chloroplasts and other organelles from damage caused by hydroxyl radicals due to hydrogen peroxide or the degradation of hydrogen peroxide $^{[14]}$. Under abiotic stress, APX expression rapidly increases in plants and in vivo ascorbic acid content changes in response to external stress, which increases the ability of plants to resist oxidative stress ${ }^{[19]}$. APX upregulation under D treatment increases the ability to reduce ROS accumulation. On the other hand, ROS can act as 
signaling molecules to mediate the expression of enzymes associated with the synthesis of secondary metabolites.

Plant respiration includes cytochrome respiration and alternative respiration, in which the terminal oxidases that transfer electrons to oxygen are cytochrome oxidase (COX) and alternative oxidase (AOX). Under normal circumstances, the electron transport chain mainly proceeds via cytochrome respiration and there is low electron leakage. However, cytochrome respiration is inhibited under stress, which blocks the electron transport chain. This causes electrons to tend to leak out and combine with oxygen to form $\operatorname{ROS}^{[20]}$. In this study, $N D 4 L$ and $C O X 1$ were upregulated under $\mathrm{K}$ treatment, and we speculate that this treatment may be similar to stress environments and interferes with the electron transport chain, causing electron leakage and oxygen binding to produce excessive ROS. At this time, the peroxidase enzyme did not show genetic responses, and $H A l$ was downregulated, resulting in decreased ATP synthesis. This affected energy supply for secondary metabolism and caused HupA accumulation to decrease $(0.57$-fold that of the $\mathrm{D}$ treatment $)$. Further research is required to understand the mechanisms by which oxidative and antioxidant systems in H. serrate-cultured thalli affect HupA biosynthesis.

\section{METHODS}

\section{Materials}

An in vitro H. serrata thallus clone (Figure 6) with the ability to synthesize HupA that was previously established by our laboratory ${ }^{[4]}$ was used.

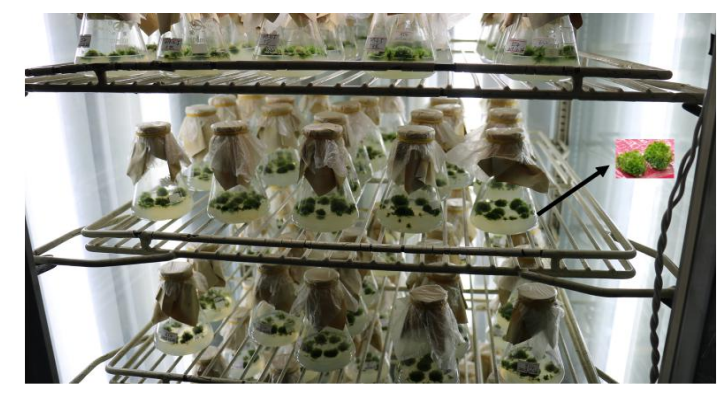

Figure 6 in vitro H. serrata thallus clone

\section{Thallus culture method and harvest ${ }^{[21]}$}

Thalli that were continuously cultured for 50 days were cut into blocks under aseptic conditions and inoculated into sterile 1/4 MS culture medium. Around $0.3 \mathrm{~g}$ of fresh 
thalli was inoculated into each culture flask, which were sealed and then placed in a $(22 \pm 2)^{\circ} \mathrm{C}$ incubator. The thalli were cultured under white light with a light intensity of $377 \mathrm{~mol} \mathrm{~m}^{-2} \mathrm{~s}^{-1}$ and a daily illumination period of $15 \mathrm{~h}$.

Thallus harvesting: Thalli were harvested after culturing for 80 days and were divided into 2 types. One type was dried, and the dry weight and HupA level were measured. Another type was stored in a $-80^{\circ} \mathrm{C}$ freezer for transcriptome sequencing (RNA-seq) and real-time fluorescence quantitative PCR (qRT-PCR).

\section{Amino acid addition}

The method of Chen ${ }^{[21]}$ was modified. Four different concentrations $(0.5,1,2$, and 4 $\mathrm{mmol} \cdot \mathrm{L}^{-1}$ ) of aspartic acid (D), lysine (K), and trytophan (W) solutions, all adjusted to $\mathrm{pH} 5.8$, were prepared and autoclaved. When thalli in section 1.2.1 were cultured for 40 days, $5 \mathrm{~mL}$ of 1 type of amino acid solution was added to each culture flask under aseptic conditions, and culture was continued for 40 days. An equal volume of sterile pure water was used as a control (CK), and each treatment was performed 5 times.

\section{Measurement of the increase in culture}

A relative increase percentage was used for comparison to eliminate the effects of differences in inoculation weight.

Relative increase percentage $=($ harvest weight-inoculation weight $) /$ inoculation weight $\times 100 \%$. Each generation was grown for 80 days.

\section{Thallus HupA extraction and measurement}

The method of Chen ${ }^{[21]}$ was modified, and fresh thalli that were cultured for 80 days were collected, washed, and dried in a $40^{\circ} \mathrm{C}$ oven until constant weight. Then, $1 \mathrm{~g}$ of powdery material was immersed in $2 \%$ tartaric acid for $24 \mathrm{~h}$, followed by $30 \mathrm{~min}$ of sonication, and the supernatant was collected after centrifugation. This process was repeated twice, in which a suitable volume of tartaric acid was added followed by 30 min of sonication. The solutions were centrifuged, the supernatants were collected and combined, and ammonia was used to adjust the $\mathrm{pH}$ to 9-10. The solution collected was evaporated to dryness and eluted with methanol to obtain a crude extract of HupA. A Shimadzu binary high-performance liquid chromatograph 
LC-20AT (Japan) was used to measure the HupA content. Chromatography conditions: chromatographic column: Waters XTerra C18 column $(4.6 \times 250 \mathrm{~mm}, 5$ $\mu \mathrm{m})$, mobile phase: methanol: ammonium acetate $=3: 7$, flow speed: $0.8 \mathrm{~mL} \cdot \mathrm{min}^{-1}$, detection wavelength: $308 \mathrm{~nm}$.

\section{RNA-seq}

Materials from the three treatments in section $1.2\left(4 \mathrm{mmol} \cdot \mathrm{L}^{-1} \mathrm{~K}, 1 \mathrm{mmol} \cdot \mathrm{L}^{-1} \mathrm{D}\right.$, and sterile water) were used. The thalli were cultured for 80 days before fresh thalli were harvested and placed in Ziploc bags on dry ice before shipping to Shanghai. Shanghai Personal Biotechnology Co., Ltd. was commissioned to carry out total RNA extraction and RNA sequencing.

\section{Total RNA extraction and sequencing procedure}

Strict sample extraction, testing, and quality control procedures were carried out from total RNA extraction to sequencing. Quality control was carried out on the samples at various steps to ensure authentic and reliable data. Figure 7 shows the operating procedure.

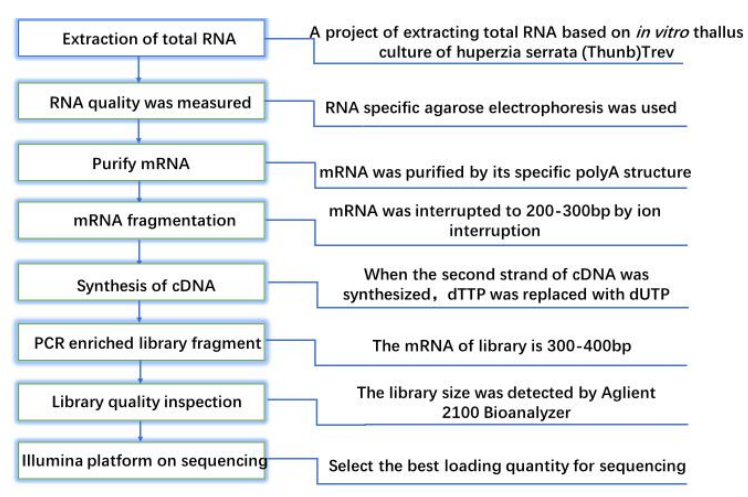

Figure 7 Operation flowchart

\section{Assembly and data management of sequencing transcripts}

A large volume of raw reads was filtered to obtain high-quality sequences (clean reads). These clean reads were de novo assembled to obtain transcript sequences before alignment and functional annotation with databases (RefSeq, NR, or genomes from phylogenetically close species). GO clustering was carried out on the transcripts. RSEM was employed for quantitation of expression levels and expressed as FPKM. 
The fold change (FC) $|\log 2(\mathrm{FC})|>1$ and gene expression change significance level (P-value) $<0.05$ were used as criteria to screen for differentially expressed genes (DEGs) between the three samples. Statistical clustering and KEGG metabolic pathway enrichment analysis were carried out on DEGs.

\section{qRT-PCR identification of differentially expressed genes}

DEGS that were enriched in KEGG metabolic pathway enrichment analysis and 1 internal reference gene (GADPH) were selected on the basis of RNA-seq. qRT-PCR was used to validate the expression levels of DEGs.

\section{Isolation and extraction of RNA samples}

The thalli that were from the three treatments in section $1.2\left(4 \mathrm{mmol} \cdot \mathrm{L}^{-1} \mathrm{~K}, 1\right.$ $\mathrm{mmol} \cdot \mathrm{L}^{-1} \mathrm{D}$, and sterile water) and were stored at $-80^{\circ} \mathrm{C}$ in a freezer were retrieved. In the experiment, 50-100 mg of tissue from every sample was mixed with $0.3 \mathrm{~mL}$ of RnaExTM reagent, and a tissue homogenizer was used to fragment cells for 5-20 s (2-3 times) before $0.7 \mathrm{~mL}$ of RnaExTM reagent was added. The samples were inverted for mixing and lysed at room temperature for $5 \mathrm{~min}$. Then, $0.2 \mathrm{~mL}$ of chloroform was added to every sample, followed by vortexing for uniform mixing. The samples were left to stand at room temperature for $2 \mathrm{~min}$, followed by centrifugation at $4^{\circ} \mathrm{C}$ and $12000 \mathrm{rpm}$ for $10 \mathrm{~min}$. Subsequently, $400 \mu \mathrm{L}$ of supernatant was added to $1.5 \mathrm{~mL}$ sterile and enzyme-free EP tubes, and $200 \mu \mathrm{L}$ anhydrous ethanol was added in a 2:1 ratio before sufficient mixing. All solutions were transferred to an adsorption column in a $2 \mathrm{~mL}$ collection tube and centrifuged at $4{ }^{\circ} \mathrm{C}$ and $8000 \mathrm{rpm}$ for 1 min. Waste fluid in the collection tube was discarded. Then, $500 \mu \mathrm{L}$ RWA buffer was added, and the tubes were centrifuged at $4{ }^{\circ} \mathrm{C}$ and $12000 \mathrm{rpm}$ for $1 \mathrm{~min}$. Waste fluid in the collection tube was discarded, and centrifugation was repeated at $4^{\circ} \mathrm{C}$ and $12000 \mathrm{rpm}$ for $1 \mathrm{~min}$. Waste fluid in the collection tube was discarded, and the column was placed into a $1.5 \mathrm{~mL}$ sterile and enzyme-free EP tube and dried for $2 \mathrm{~min}$. Then, $50 \mu \mathrm{L}$ DEPC-treated water was added to the center of the membrane to dissolve RNA followed by incubatation at room temperature for $2 \mathrm{~min}$. Finally, the tubes were centrifuged at $4{ }^{\circ} \mathrm{C}$ and $12000 \mathrm{rpm}$ for $1 \mathrm{~min}$ for RNA collection. OD values were 
measured, and electrophoresis was carried out. Reverse transcription was carried out or tubes were stored at $-20^{\circ} \mathrm{C}$ for subsequent experiments.

\section{Primer design and selection}

Primer Premier Version 6 (Premier Biosoft Inc., CA) was used to design primers for the DEG sequences from section 1.5.2 and the sequence of the internal reference $G A P D$. Two sets of primers were designed for each gene. Amplification melt curves (Figure 8) were used to select one set of primers (Table 5). An ABI7900 fluorescence quantitative PCR machine (USA) was used for quantitation.

Table5 Primers for qRT-PCR to verify the nineteen genes involved in HuperzineA biosynthesis in Huperzia serrata

\begin{tabular}{|c|c|c|c|c|}
\hline Gene name & Gene ID & $\begin{array}{l}\text { Gene function } \\
\text { name }\end{array}$ & $\begin{array}{c}\text { Primer sequences } \\
\qquad\left(5^{\prime}-3^{\prime}\right)\end{array}$ & $\begin{array}{l}\text { Amplificat } \\
\text { ion length } \\
\text { (bp) }\end{array}$ \\
\hline PANK1 & 53354 & $\begin{array}{l}\text { pantothenic } \\
\text { acid kinase }\end{array}$ & $\begin{array}{l}\text { F:AGGCAAGGGAACAAC } \\
\text { TACC } \\
\text { R:AGAAGGTGACGCAGA } \\
\text { TGAA }\end{array}$ & 153 \\
\hline$A P X$ & 837304 & $\begin{array}{l}\text { L-ascorbic } \\
\quad \text { acid } \\
\text { peroxidase }\end{array}$ & $\begin{array}{l}\text { F:GATTGGAACAAAACA } \\
\text { GCCA } \\
\text { R:CAAGAGCAGCATTAT } \\
\text { CAAACA }\end{array}$ & 174 \\
\hline$C O X 1$ & 4512 & $\begin{array}{c}\text { Oxidative } \\
\text { phosphorylation }\end{array}$ & $\begin{array}{l}\text { F:GAAAGAACATGAGGG } \\
\text { GTACAA } \\
\text { R:GCCGTAGCACCAAAG } \\
\text { ATTA }\end{array}$ & 100 \\
\hline$N D 4 L$ & 4539 & $\begin{array}{l}\text { NADH-ubiquin } \\
\text { one } \\
\text { oxidoreductase } \\
\text { chain } 4\end{array}$ & $\begin{array}{l}\text { F:GAGAAGAGAGAAAA } \\
\text { GGGGAAA } \\
\text { R:CAACAAAGGACATAG } \\
\text { GATGAGA }\end{array}$ & 90 \\
\hline$H A 1$ & 816413 & $\begin{array}{c}\mathrm{H}+\text {-transporting } \\
\text { ATPase }\end{array}$ & $\begin{array}{l}\text { F:GGCTCTCCATCTTGGT } \\
\text { GTT } \\
\text { R:AAGCGTCCTTGTTTTG } \\
\text { TCC }\end{array}$ & 137 \\
\hline$G D H 2$ & 851311 & $\begin{array}{c}\text { Glutamate } \\
\text { dehydrogenase }\end{array}$ & $\begin{array}{l}\text { F:TCAAAGAAAGGAGTC } \\
\text { ACCATC } \\
\text { R:TCTCATCCCACATAA }\end{array}$ & 109 \\
\hline
\end{tabular}




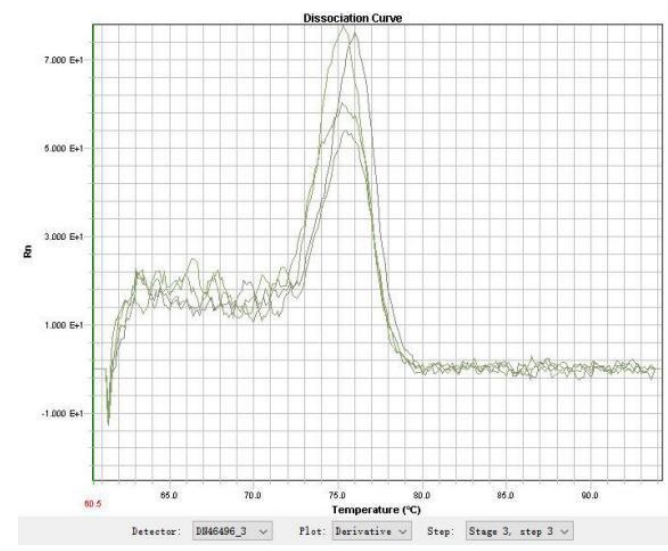

A. APX melting curve

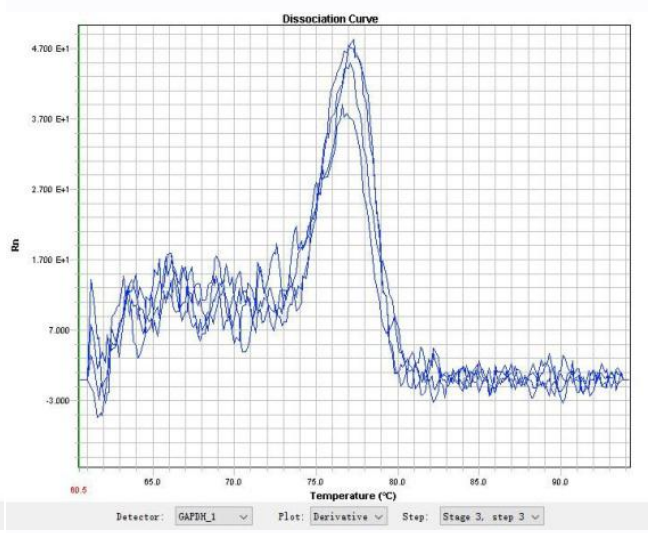

B. GAPD Hmelting curve

Figure 8 The designed primers were dissolved in the phylloids of shizhen snakefoot

\section{Calculation of the relative expression level (RQ) copy number}

RQ was calculated by the $2^{-\Delta \Delta \mathrm{Ct}}$ method $^{[22]}$, where the CT value was the mean of 3 wells.

\section{List of abbreviations}

DEGs:differentially expressed genes;

D:aspartic acid;

DW:dry weight;

K:lysine;

W:trytophan;

CAO:copper amine oxidase;

PANK1:pantothenic acid kinase;

APX:L-ascorbic acid peroxidase;

COX1:Oxidative phosphorylation;

ND4L:NADH-ubiquinone oxidoreductase chain 4;

HA1:H+-transporting ATPase;

GDH2:Glutamate dehydrogenase;

GAPDH:glyceraldehyde-3-phosphate dehydrogenase;

RQ:relative expression level copy number;

PANK1:pantothenic acid kinase; 
APX:L-ascorbic acid peroxidase;

COXI:Oxidative phosphorylation;

ND4L:NADH-ubiquinone oxidoreductase chain 4;

HAl:H+-transporting ATPase;

GDH2: Glutamate dehydrogenase;

GAPDH:glyceraldehyde-3-phosphate dehydrogenase;

\section{Acknowledgements}

We thank Professor Zhan-Yuan Huai (LuShan Botanical Garden,Chinese Academy of sciences, LuShan, China) for his kind help in the authentication of the Huperzia serrata (Thunb)Trev plants.

\section{Authors' contributions}

YYX and TYS contributed equally to this work. All authors read and approved the final manuscript.

\section{Funding}

The present study was supported by the National Natural Science Foundation Item (81660597); National Natural Science Foundation of China (81360614);Natural Science Foundation Item of Jiangxi Provincial (20132BAB204023)

\section{Competing interests}

The authors declare that they have no competing interests. We declare that all authors have read and approved the manuscript, and we have no financial and personal relationships with other people or organizations that can inappropriately influence our work, there is no professional or other personal interest of any nature or kind in any product, service and/or company that could be construed as influencing the position presented in, or the review of, the manuscript entitled.

\section{Reference}

1. Wu H, Zhuang P, Feng ZC, et al. Resource investigation and assessment of Huperzia serrata [J]. Journal of Natural Resources, 2005, 20(1): 59-67.

2. Xu HB, Wang XP, Liu GL. Pharmacological studies and clinical application of huperzine A [J]. World Clinical Drugs , 2014, 35(1):60-63.

3. Zhang HY, Tang XC. Neuroprotective effects of Huperzine A: new therapeutic targets for neurodegenerative disease [J]. Trends in Pharmacological Sciencces, 2007, 27(12): 619-625.

4. Ji ZD, Tu YS, Chen M, et al. Conditional optimization and kinetic research on producing huperzine A using Huperzia serrata in vitro [J]. Chinese Traditional and Herbal Drugs, 2016,47(3): 488-492.

5. Xu XZ, Tu YS, Ji ZD, et al. In vitro-cultured morphological changes in Huperzia serrata and accumulation of Huperzine A [J]. Bulletin of Botany, 2015, 50(6): 733-738. 
6. Huang YX, Tan HX, Yu J, et al.Advances in study on secondary metabolic engineering of alkaloids in medicinal plants [J]. Chinese Traditional and Herbal Drugs, 2016, 47(23): 4271-4281.

7. Chen YQ, Zhu WH. Tissue, cell and embryo culture of Taxus [J]. Plant Physiology Journal, 1997(03): 213-219.

8. Ye LN, Tu YS, Huang Q, et al. Studies on $\mathrm{H} 2 \mathrm{O} 2$ induced effect on Huperzia serrata in vitro [J]. Journal of Tropical and Subtropical Botany, 2017, 25(6):587-593.

9. Zhang GW, Wang WJ, Zhang XM, et al. Denovo RNA sequencing and transcriptome analysis of Colletotrichum gloeosporioides ES026 reveal genes related to biosynthesis of huperzine A [J]. Plos One, 2015, 10(3):e0120809.

10. Yang MQ, You WJ, Wu SW, et al. Global transcriptome analysis of Huperzia serrata, and identification of critical genes involved in the biosynthesis of huperzine $\mathrm{A}[\mathrm{J}]$. Bmc Genomics, 2017, 18(1):24.

11. Trinity software website.https://www.broadinstitute.org/.

12. Gu RH, Hong LY, Long CL. The ways of producing secondary metabolites via plant cell culture [J]. Plant Physiology Journal, 2013, 49 (09): 869-881.

13. Jiang XX, Li YC, Chao D, et al. Effect of L-tryptophan and its derivatives on cephalotaxine production in Cephalotaxu mannii suspension cells [J]. Chinese Traditional and Herbal Drugs , 2016, 47(20): 3696-3701.

14. Castillo M, Gupta R N, Maclean D B, et al. Biosynthesis of lycopodine from lysine and acetate. The pelletierine h [J]. Canadian Journal of Chemistry, 1970, 48(12): 1893-1903.

15. Chen ZY, Zhang JC. Research progress of pathway involved in Huperzinine biosynthesis and development regulation [J]. China Journal of Traditional Chinese Medicine and Pharmacy, 2013(6): 1815-1818.

16. Yang YH, Zhao JX, Wang H, Bai R, Han M. Pantothenate Kinase and Its Inhibitors:Current Research Status [A]. Progress in pharmaceutical science, 2014,38(9):641-648.

17. Zhang L, Wan QH, Gao WY. Advances in study of hyperzine A [J]. Chinese Traditional and Herbal Drugs, 2005,36(9):1422-1426.

18. Yu Xiao, Tu YS, Ye LN, et al. TMT proteomics and bioinformatics to analyze protein differences in different Hup A content of thallus of Huperzia serrate [J]. Chinese Traditional and Herbal Drugs, 2019,50(12): 2950-2958.

19. Chen SY, Xi XH, Tong MS, et al. treak laver ascorbic acid peroxidase gene cloning and bioinformatics analysis[J]. Tianjin Agricultural Sciences, 2014,20(4):8-10.

20. Liu Q, Liu ZW, He GH, Hu C. Effects of Aluminum Stress on Respiration and Reactive Oxygen Metabolism in Leaves of Tobacco Seedlings [J]. Acta Agriculturae Universitatis Jiangxiensis, 2017, 39( 1): $37-42$.

21. Chen $\mathrm{M}, \mathrm{Tu} \mathrm{YS}, \mathrm{Ye} \mathrm{LN}$, et al. Effect of amino acids on thallus growth and Huperzine-A accumulation in Huperzia serrata [J]. Bulletin of Botany, 2017, 52(02): 218-224.

22. Livak K J, Schmittgen T D.Analysis of relative gene expression data using real-time quantitative PCR and the $2{ }^{\triangle{ }^{\wedge C t}}$ Method.Methods ,2001, 25(4):402-408 



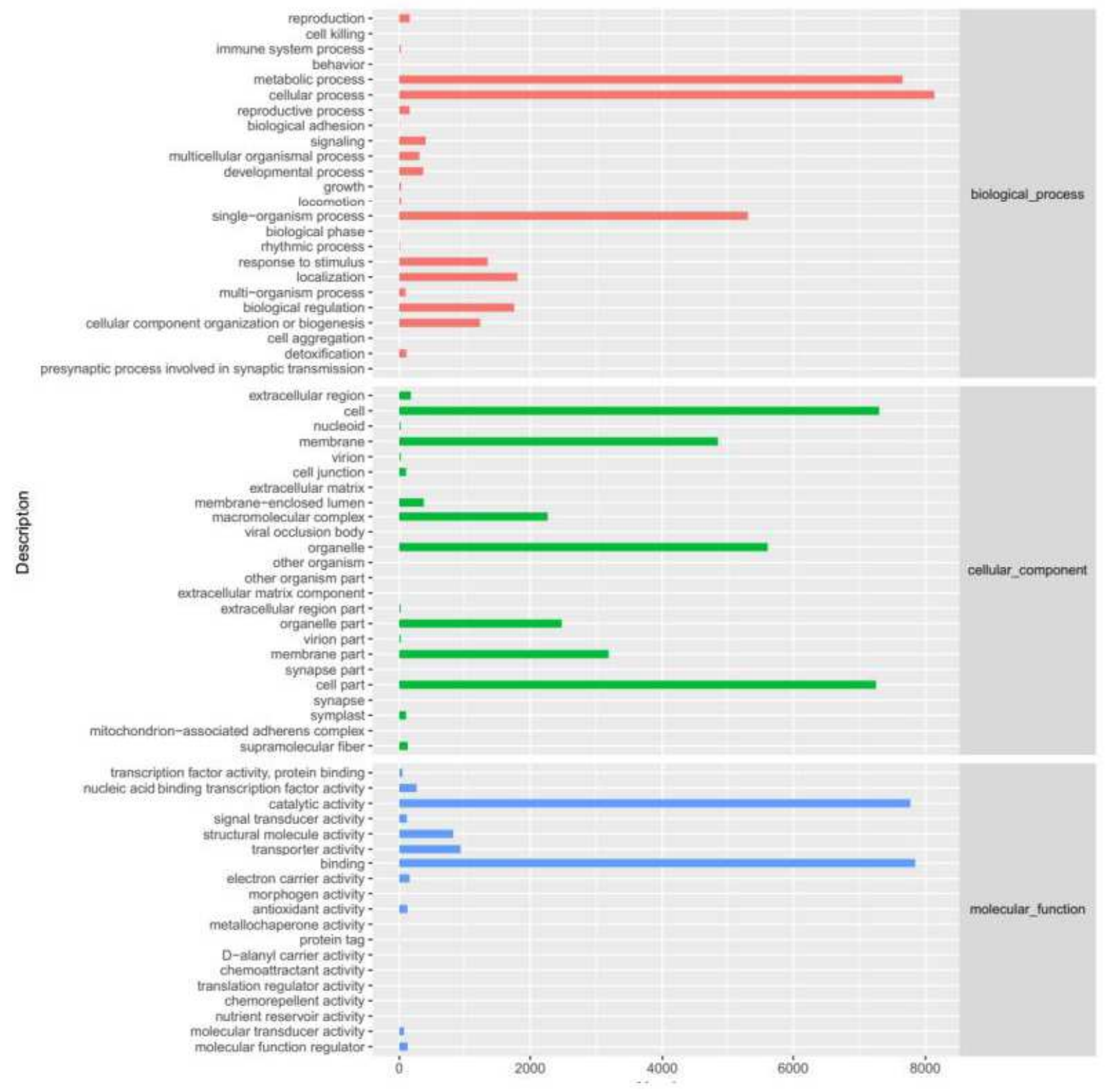

Figure 2

GO function note 


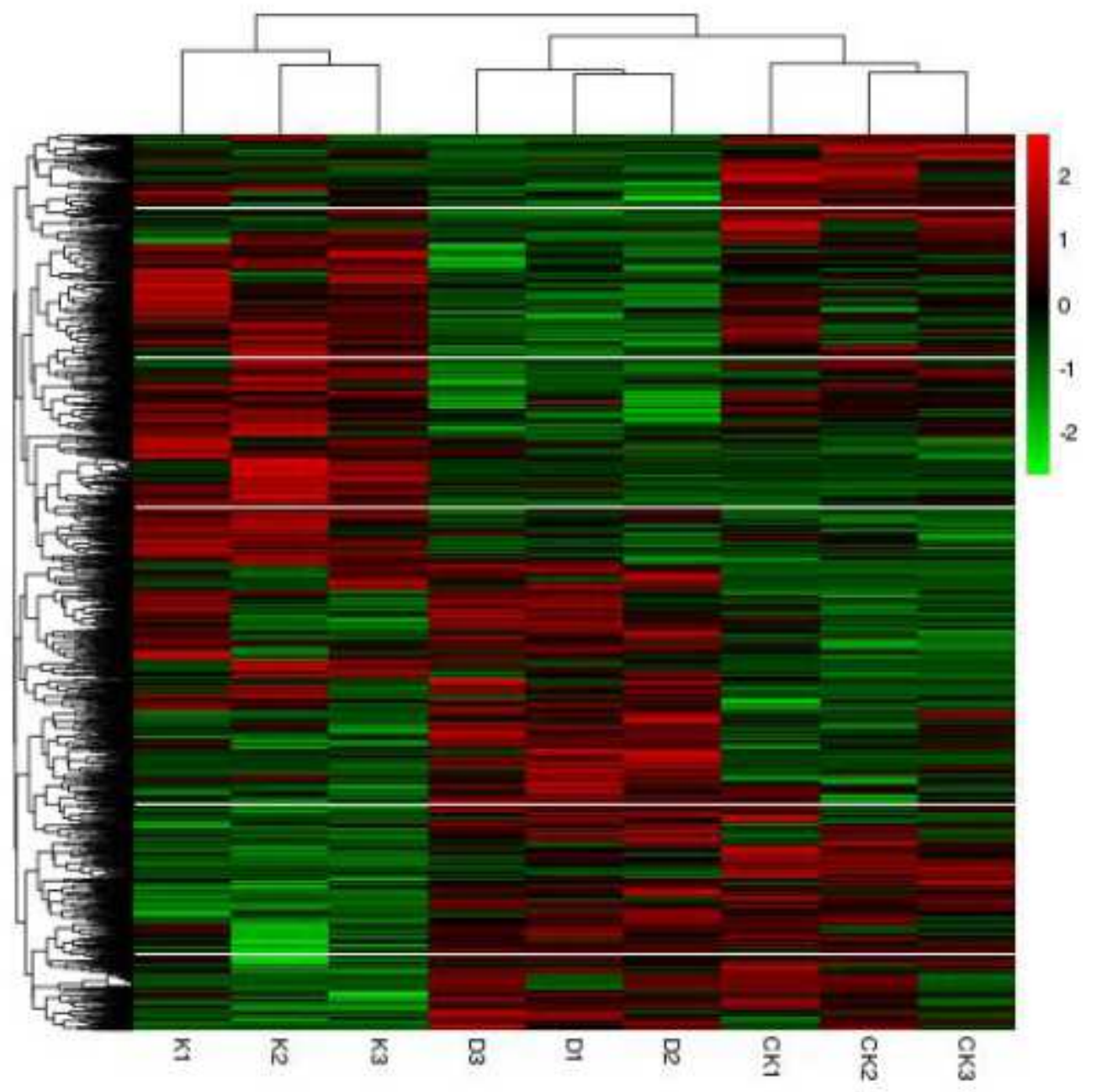

Figure 4

Cluster tree map of differentially expressed genes

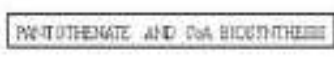

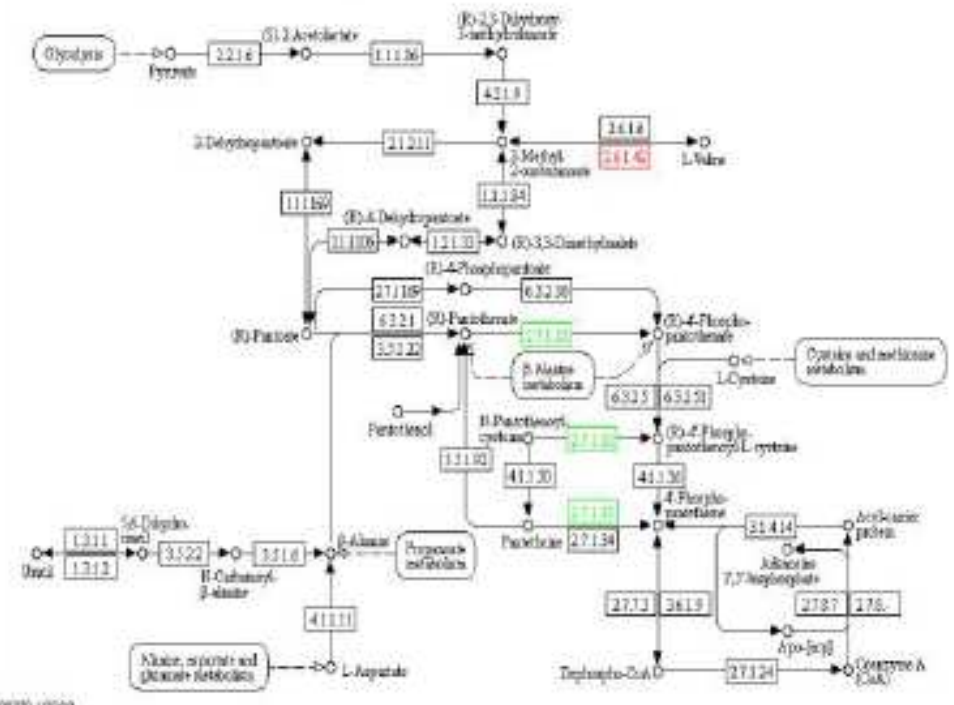


Figure 6

D VS K Pantothenate and CoA biosynthesis

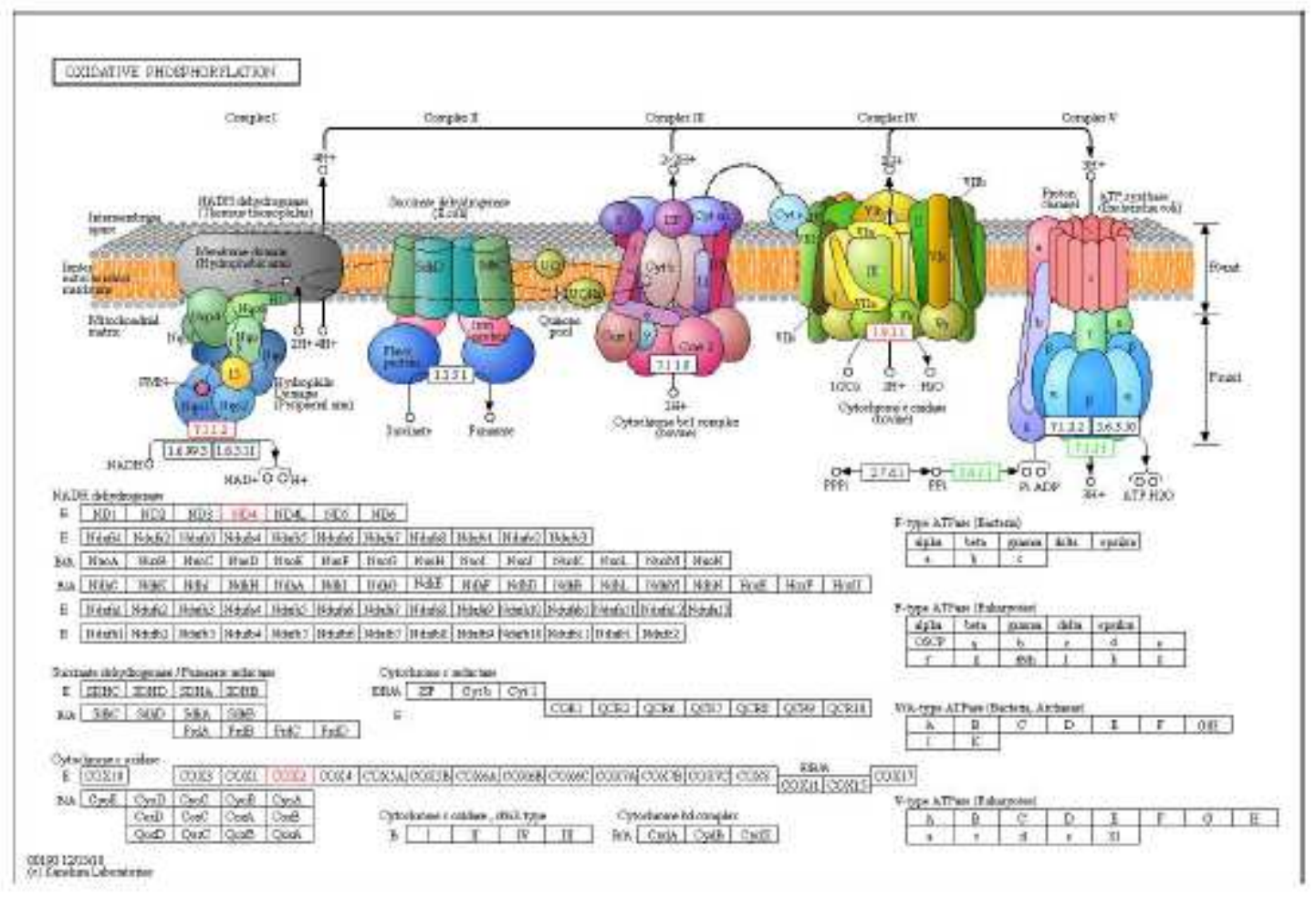

Figure 8

D vs K Oxidative phosphorylation
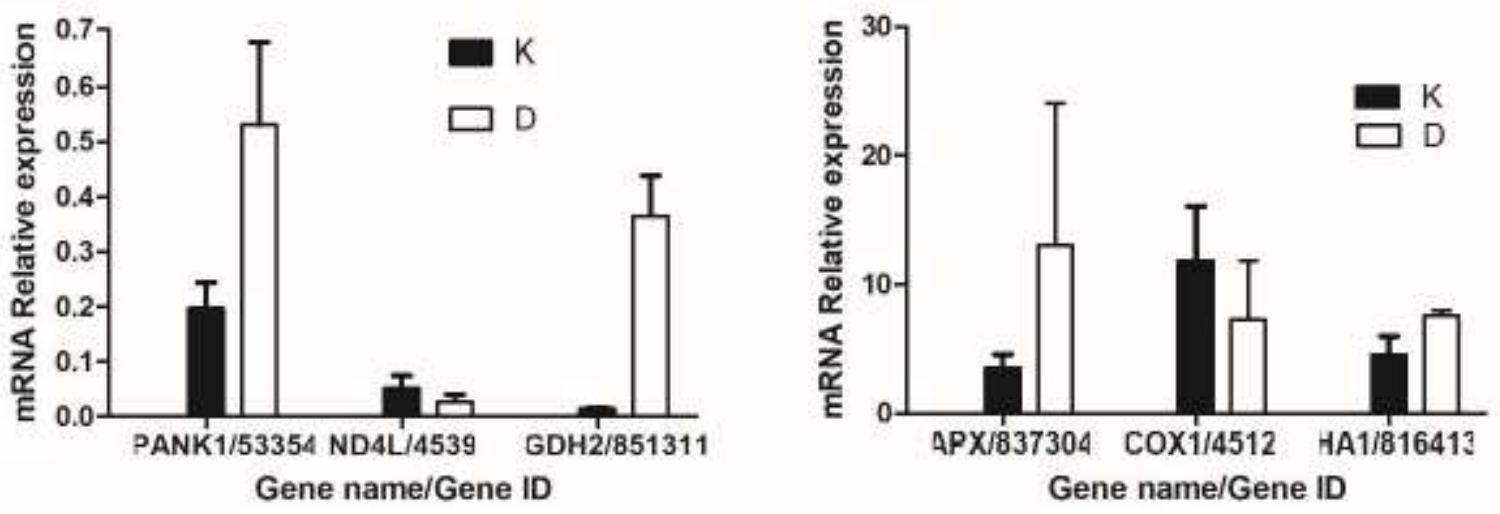

Figure 10

mRNA relative expression by $q R T-P C R \otimes P<0.05 \rrbracket$ 


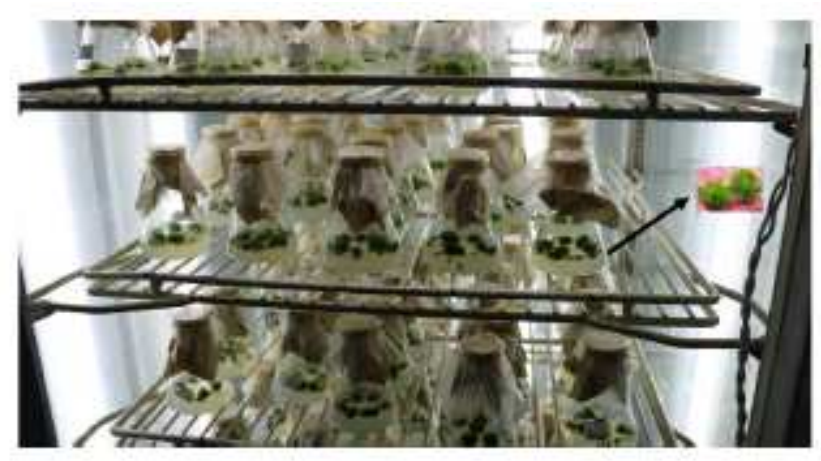

Figure 12

in vitro $\mathrm{H}$. serrata thallus clone

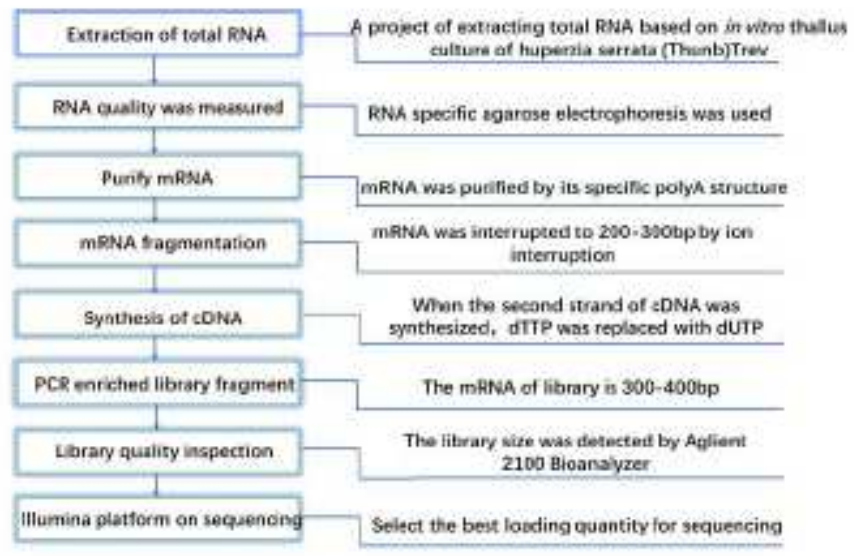

Figure 14

Operation flowchart

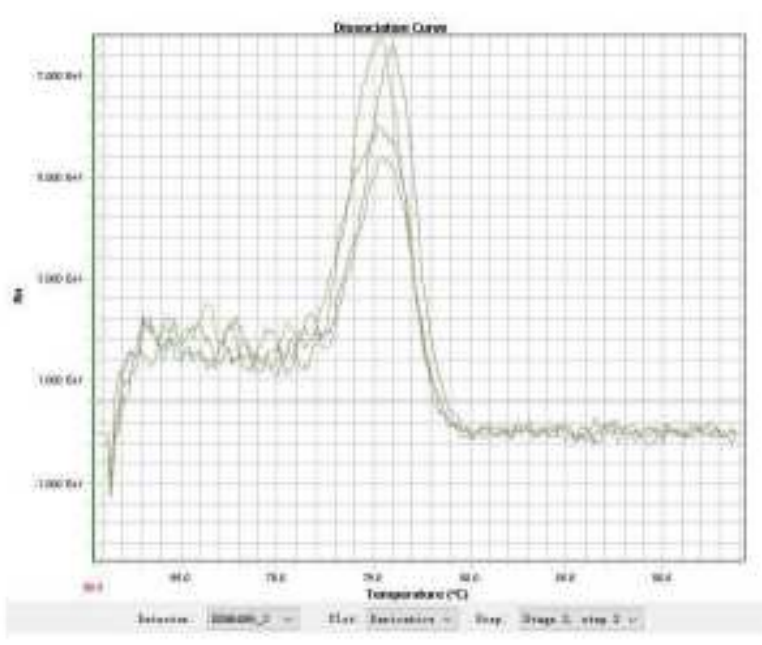

A. APX melting curve

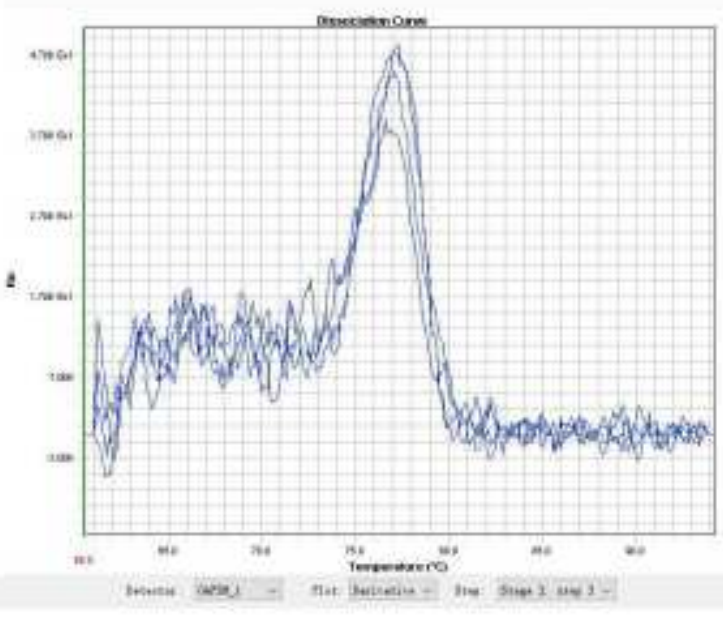

B. GAPD Hmelting curve 
The designed primers were dissolved in the phylloids of shizhen snakefoot 